\title{
Papers
}

\section{Long term mortality after severe starvation during the siege of Leningrad: prospective cohort study}

Pär Sparén, Denny Vågerö, Dmitri B Shestov, Svetlana Plavinskaja, Nina Parfenova, Valeri Hoptiar, Dominique Paturot, Maria Rosaria Galanti

\begin{abstract}
Objectives To determine whether starvation during periods of increased growth after birth have long term health consequences.

Design Analysis of cardiovascular risk factors and mortality in a longitudinal follow up after the 1941-4 siege of Leningrad.

Mortality measured from 1975 up to the end of 1999.

Setting St Petersburg, Russia (formerly Leningrad).

Participants 5000 men born 1916-35 who lived in Leningrad, randomly selected to take part in health examinations in 1975-7. Of the 3905 men who participated, a third had experienced the siege.

Main outcome measures Relative risk of ischaemic heart disease and mortality from stroke by siege exposure. Odds ratios and means for several cardiovascular risk factors.

Results Three to six decades after the siege, in men who experienced the siege around the age of puberty blood pressure was raised (mean difference in systolic $3.3 \mathrm{~mm} \mathrm{Hg}$, in diastolic $1.3 \mathrm{~mm} \mathrm{Hg}$ ) as was mortality from ischaemic heart disease (relative risk $1.39,95 \%$ confidence interval 1.07 to 1.79 ) and stroke (1.67, 1.15 to 2.43), including haemorrhagic stroke (1.71, 0.90 to 3.22$)$. The effect on mortality was partly mediated via blood pressure but not by any other measured biological, behavioural, or social factor.

Conclusions Starvation, or accompanying chronic stress, particularly at the onset of or during puberty, may increase vulnerability to later cardiovascular disease.
\end{abstract}

\section{Introduction}

Famine and food shortage have both short and long term consequences for health. Particular concern has arisen for later consequences of in utero starvation, a concern reinforced by much new research suggesting that impaired foetal growth is indeed linked to increased risk of heart disease, stroke, and diabetes in adult life. Studies of the Dutch hunger winter (1944-5) showed that the average birth weight for babies conceived or born during that winter was around $300 \mathrm{~g}$ lower. ${ }^{1}$ The siege of Leningrad (1941-4) was associated with an average fall in birth weight of $500-600 \mathrm{~g}$ (for term babies born in 1942). Of those born in the first half of 1942, half weighed less than $2500 \mathrm{~g} .{ }^{2}$ On the basis of previous studies we estimate that a fall of 500-600 $\mathrm{g}$ in birth weight would correspond to an average increase in blood pressure of 1-2 $\mathrm{mm} \mathrm{Hg}$ in adult life, ${ }^{3}$ a $15 \%$ increased risk of mortality from ischaemic heart disease, ${ }^{4}$ and a $35 \%$ increased risk of haemorrhagic stroke. ${ }^{5}$
Follow up of 549 children born in or near Leningrad before or during the siege, however, concluded that there was no effect of intrauterine malnutrition on blood pressure, glucose intolerance, or lipid concentrations in adult life. ${ }^{6}$ Studying the Dutch hunger winter Roseboom et al concluded that starvation in mid or late fetal period did not carry an increased risk of an atherogenic lipid profile ${ }^{7}$ or heart disease later in life, ${ }^{8}$ while exposure in early gestation did. Bygren et al reported no excess mortality (at age 40-70) among individuals starved during the whole fetal period. ${ }^{9}$ In contrast, those who starved during part of it (early or late) were more likely to die from stroke. Kannisto et al, studying Finnish birth cohorts born around the 1866-8 famine, concluded that starvation in utero, infancy, or early childhood was not linked to mortality in adult life (at age 17-80). ${ }^{10}$ Typically, groups who experienced starvation during (part of) fetal life were compared with groups starving in other parts of fetal or early life, on the assumption that only one specific fetal period programs vulnerability to a specific disease.

These inconsistencies call for a more precise understanding of how and when starvation affects health. Does starvation outside the fetal period, say maternal starvation before pregnancy or offspring's starvation after birth, also have long term effects? Recent work on self starvation among young girls cautions against narrowing the age interval of exposure in studies of malnutrition or starvation. ${ }^{11}$ Before the fetal origins hypothesis most research did use a broader exposure. ${ }^{12-14}$ Kermack et al suggested that "the important factor from the point of view of the health of the individual during his life is his environment up to age of say 15 years." ${ }^{12}$

We studied the long term health consequences of involuntary starvation in a population of men who were aged 6 -28 years at the peak of the period of severe food shortage. German troops prevented supplies from reaching Leningrad from 8 September 1941 to 27 January 1944. Of a population of 2.9 million (including 0.5 million children), 630000 died from hunger-related causes, ${ }^{15}$ most during the winter of 1941-2. We investigated whether experience of the siege did in fact lead to an increased risk of mortality, particularly from cardiovascular disease.

\section{Methods}

Study base and data collection

As part of the 1973 US-Soviet collaborative programme, both countries collected data under the same research protocol, the lipid research clinics programme. ${ }^{16}$ A baseline survey was undertaken in Leningrad 1975-7, in which 5000 men born in 1916-35 were randomly selected from voting lists in the socially mixed 
Petrogradsky district; 3905 men (78\%) participated. Data were collected on socioeconomic factors (education, occupation, and marital status), behaviour (smoking and alcohol consumption), anthropometric measures (weight, height, and skinfold thickness), and other biological measurements (diastolic and systolic blood pressure, low density and high density lipoprotein cholesterol concentration, and a Rose questionnaire interview about cardiovascular dysfunction). Nearly a third $(\mathrm{n}=1406)$ had lived in Leningrad during the siege, which normally meant that they spent the whole siege period there as most people were unable to leave.

We followed mortality from the time of the interview to 31 December 1999. The vital status of the cohort members was ascertained through contacts with the participants themselves and their relatives or neighbours. Address bureaux were used for those who had moved. The 132 participants who were lost before the end of follow up were censored at the last day of contact. We obtained death certificates to determine the date of death and coded cause according to ICD-8 (international classification of diseases, eight revision) (cardiovascular 390-458, ischaemic heart disease 410-414, stroke 430-438, and haemorrhagic stroke 430431). We coded cause of death carefully and usually only after contact with the hospital where the person had been registered. The lipid research clinics study focused especially on circulatory disease. Due to a mistake during the initial interviews we did not have information for certain socioeconomic and behavioural variables for 672 men. Sensitivity analysis showed that risk estimates were virtually identical between the full and the restricted sample.

\section{Food shortage}

From 20 November 1941 bread rations in Leningrad were at their lowest: $250 \mathrm{~g}$ daily for manual workers and $125 \mathrm{~g}$ for other civilians. Children below the age of 12 belonged to the latter category, but children over 12 years received even less-for example, only $200 \mathrm{~g}$ of fat, $800 \mathrm{~g}$ of sugar, and $600 \mathrm{~g}$ of carbohydrate a month. If rations were received in full, which was not always the case, this amounted to about 460 calories a day. ${ }^{15}$ Stanner et al estimated the average daily ration to be around 300 calories, containing virtually no protein. ${ }^{6}$ This is extremely low, even compared with rations during the Dutch hunger winter. ${ }^{1}$

\section{Statistical analyses}

We used Poisson regression to calculate relative risks, where the number of deaths was weighted by the person years at risk in each combination of the explanatory variables. ${ }^{17}$ Residence in Leningrad during the siege (yes/no) and age at siege $(\leq 8,9-15$, 16 -26 years $v$ not in siege) were introduced into successive regression models with other explanatory factors. We always controlled for birth year and attained age. Likelihood ratio tests were used to test models against each other. ${ }^{18}$ We examined whether there was any difference in risk of mortality between those living in Leningrad during the siege and those who were not; whether any effect was modified by age at exposure; and whether any effect was of similar magnitude during the whole follow up period.

To assess socioeconomic confounding we adjusted risk estimates for marital status (married, not married, divorced, widowed), education (university degree, incomplete university, up to 10 years of schooling, up to 7 years, less than 7 years, and no schooling), and occupational class (manual, non-manual, and other) at baseline (interview). We also adjusted for smoking and alcohol consumption. Smoking was grouped into ever or never and alcohol consumption (frequency of drinking in the week before the interview) into four categories (never, every day, 3-4 times a week, 1-2 times a week or less often).

Intermediate outcomes-namely, adult body mass index, adult height, skinfold thickness measured at the arm, diastolic and systolic blood pressure, and the ratio of low to high density lipoprotein cholesterol-were considered as potential mediators between starvation and later cardiovascular disease. BMI was classified into overweight versus normal $(\geq 25 v<25)$ and obese versus normal and overweight $(\geq 30 v<30)$, which were analysed separately; skinfold thickness and cholesterol ratio were dichotomised at the mean plus one SD (15.3 mm and 4.0, respectively). Body height was dichotomised at the mean minus one SD $(163 \mathrm{~cm})$. Blood pressure was categorised as normal or raised (systolic $\geq 160 \mathrm{~mm} \mathrm{Hg}$; diastolic $\geq 95 \mathrm{~mm} \mathrm{Hg}$ ). The latter included those on medication for high blood pressure. We used biological risk indicators as dichotomised outcome variables in logistic regression models ${ }^{18}$ to estimate odds ratios by siege experience. They were also treated as continuous outcome variables in linear regression models to estimate mean differences.

We carried out two tests for heterogeneity. A likelihood ratio test indicated whether the outcome was equally likely in each of the four categories (age at siege: $\leq 8,9-15,16-26$, and not in siege). A Wald test showed whether the effect was the same in ages $9-15$ as in ages $\leq 8$ or $16-26$.

\section{Results}

Table 1 shows intermediate outcomes before the start of the mortality follow up. There was a significant excess risk of high systolic and diastolic blood pressure in men who lived through the siege. Those who were around the age of puberty (9-15 years) at the peak of starvation (January 1942) were especially prone to high systolic blood pressure (odds ratio $1.56,95 \%$ confidence interval 1.21 to 2.02) with a mean excess of $3.3 \mathrm{~mm} \mathrm{Hg}$ (Wald test $\mathrm{P}=0.03$ ). Except for a tendency to have a greater skinfold thickness, all other indicators of cardiovascular risk were remarkably similar for exposed and non-exposed.

During follow up 2048 of the 3905 men died. Cardiovascular disease accounted for 1050 deaths (51\%), 662 from ischaemic heart disease and 333 from stroke, 97 of which were haemorrhagic. The excess risk of dying (all causes) for those who experienced the siege was $21 \%$ (relative risk $1.21,1.10$ to 1.32 ) (data not shown).

Table 2 (restricted sample) shows the excess risk of dying from ischaemic heart disease (1.28, 1.08 to 1.51). Among those aged $9-15$ at the peak of starvation this estimate was 1.39 (1.07 to 1.79). The effects of starvation around puberty were stronger still for stroke (1.67, 1.15 to 2.43), including haemorrhagic stroke (1.71, 0.90 to 3.22$)$. For stroke, but not for other mortality, the siege effect was significantly stronger for those who experienced it around puberty than at other ages (Wald test $\mathrm{P}=0.02$ ).

Adjustment for occupation, education, marital status, smoking, or alcohol consumption had no impact on risk estimates, although all these variables were themselves strongly correlated with mortality. Among those aged 9-15 years adjustment for systolic and diastolic blood pressure changed risk estimates downwards from 1.39 to 1.29 for ischaemic heart disease, from 1.67 to 1.49 for stroke, and from 1.71 to 1.51 for haemorrhagic stroke. Addition of other intermediate outcomes rendered small changes.

Throughout the follow up period there was a pattern of higher cardiovascular mortality for those who experienced the siege (figure). This was particularly pronounced in 1987-91, when those who did not experience the siege seemed to have a 
Table 1 Intermediate outcomes measured at recruitment of cohort in 1975-7. Probability measures are odds ratios for dichotomous outcomes (estimated with logistic regression models) and mean differences for continuous outcomes (estimated with linear regression models), both with $95 \%$ confidence intervals. All estimates adjusted for birth cohort

\begin{tabular}{|c|c|c|c|c|c|c|c|}
\hline \multirow[b]{2}{*}{ Dependent variable } & \multirow[b]{2}{*}{ Any age } & \multicolumn{3}{|c|}{ Age at siege (years) } & \multirow[b]{2}{*}{$\begin{array}{c}\text { Not in siege } \\
\text { (reference) }\end{array}$} & \multicolumn{2}{|c|}{ Tests for heterogeneity } \\
\hline & & $\leq 8$ & $9-15$ & $16-26$ & & $\begin{array}{l}\mathrm{LR}^{*} \mathrm{P} \\
\text { value }\end{array}$ & $\begin{array}{c}\text { Waldt } P \\
\text { value }\end{array}$ \\
\hline Overweight $(\mathrm{BMI} \geq 25)$ & 0.89 (0.78 to 1.02) & $0.90 \quad$ (0.64 to 1.27$)$ & 0.83 (0.69 to 1.00$)$ & 0.97 (0.78 to 1.20$)$ & 1.00 & 0.25 & 0.29 \\
\hline$\overline{\text { Obesity (BMI } \geq 30 \text { ) }}$ & $1.00 \quad$ (0.82 to 1.22$)$ & $0.95 \quad$ (0.52 to 1.75$)$ & 1.13 (0.85 to 1.50$)$ & 0.90 (0.68 to 1.21$)$ & 1.00 & 0.79 & 0.31 \\
\hline Difference in BMI & $-0.16(-0.38$ to 0.07$)$ & $-0.31(-0.90$ to 0.27$)$ & $-0.19(-0.50$ to 0.13$)$ & $-0.07(-0.43$ to 0.28$)$ & 0.00 & 0.51 & 0.86 \\
\hline Height $\leq 163 \mathrm{~cm}$ & $0.91 \quad(0.75$ to 1.10$)$ & $0.90 \quad$ (0.54 to 1.49) & $0.91 \quad(0.70$ to 1.19$)$ & 0.92 (0.68 to 1.24$)$ & 1.00 & 0.82 & 0.99 \\
\hline Difference in height $(\mathrm{cm})$ & $0.12(-0.29$ to 0.54$)$ & $0.42(-0.66$ to 1.50$)$ & $-0.20(-0.78$ to 0.38$)$ & $0.44(-0.22$ to 1.09$)$ & 0.00 & 0.41 & 0.11 \\
\hline $\begin{array}{l}\text { Skinfold thickness } \geq 15.3 \\
\mathrm{~mm}\end{array}$ & $1.14 \quad(0.95$ to 1.37$)$ & 1.17 (0.70 to 1.96) & 1.15 (0.89 to 1.50$)$ & 1.12 (0.85 to 1.48$)$ & 1.00 & 0.59 & 0.97 \\
\hline $\begin{array}{l}\text { Difference in skinfold } \\
\text { thickness }(\mathrm{mm})\end{array}$ & $0.15(-0.16$ to 0.47$)$ & $-0.09(-0.90$ to 0.72$)$ & $0.17(-0.26$ to 0.60$)$ & $0.20(-0.29$ to 0.70$)$ & 0.00 & 0.72 & 0.84 \\
\hline LDL/HDL cholesterol $\geq 4$ & $1.03 \quad$ (0.86 to 1.23) & 0.88 (0.54 to 1.44) & 1.09 (0.84 to 1.39$)$ & $1.01 \quad$ (0.77 to 1.33$)$ & 1.00 & 0.84 & 0.49 \\
\hline $\begin{array}{l}\text { Difference in LDL/HDL } \\
\text { cholesterol }\end{array}$ & $-0.02(-0.10$ to 0.06$)$ & $-0.01(-0.22$ to 0.19$)$ & $-0.01(-0.12$ to 0.10$)$ & $-0.04(-0.16$ to 0.08$)$ & 0.00 & 0.93 & 0.78 \\
\hline Systolic BP $\geq 160 \mathrm{~mm} \mathrm{Hg}$ & $1.30 \quad$ (1.10 to 1.54$)$ & $0.64 \quad(0.33$ to 1.25$)$ & 1.56 (1.21 to 2.02$)$ & 1.22 (0.97 to 1.53$)$ & 1.00 & 0.0006 & 0.03 \\
\hline $\begin{array}{l}\text { Difference in systolic BP } \\
(\mathrm{mm} \mathrm{Hg})\end{array}$ & 1.88 (0.44 to 3.32$)$ & -2.02 (-5.75 to 1.71$)$ & 3.26 (1.27 to 5.26$)$ & $1.32(-0.95$ to 3.59$)$ & 0.00 & 0.003 & 0.03 \\
\hline Diastolic BP $\geq 95 \mathrm{~mm} \mathrm{Hg}$ & 1.18 (1.03 to 1.35$)$ & 0.92 (0.63 to 1.35$)$ & 1.20 (0.99 to 1.45$)$ & 1.23 (0.99 to 1.52$)$ & 1.00 & 0.07 & 0.71 \\
\hline $\begin{array}{l}\text { Difference in diastolic BP } \\
(\mathrm{mm} \mathrm{Hg})\end{array}$ & 0.87 (0.07 to 1.67$)$ & $-1.35(-3.41$ to 1.32$)$ & 1.33 (0.23 to 2.44) & $0.95(-0.31$ to 2.20$)$ & 0.00 & 0.02 & 0.14 \\
\hline Coronary heart diseaseł & $1.07 \quad$ (0.88 to 1.29$)$ & 0.49 (0.22 to 1.09$)$ & 1.19 (0.90 to 1.58$)$ & 1.07 (0.82 to 1.39$)$ & 1.00 & 0.12 & 0.21 \\
\hline
\end{tabular}

BMI=body mass index

LDL/HDL=low density lipoprotein/high density lipoprotein.

*Likelihood ratio test that outcome was equally likely in each category ( $\leq 8,9-15,16-26$, not in siege). Under the null hypothesis the test statistic has $\chi^{2}$ distribution with 3 df

†Wald test that siege effect was same for those aged 9-15 at siege as for those aged $\leq 8$ or 16-26. Under the null hypothesis the test statistic has $\chi^{2}$ distribution with $1 \mathrm{df}$.

†Presence according to Rose questionnaire.

Table 2 Cardiovascular mortality 1975-99 for restricted sample* by age at siege exposure. Relative risks and $95 \%$ confidence intervals as estimated with Poisson regression models $†$

\begin{tabular}{|c|c|c|c|c|c|c|c|}
\hline \multirow[b]{2}{*}{ Cause of death } & \multirow[b]{2}{*}{ Any age } & \multicolumn{3}{|c|}{ Age at siege (years) } & \multirow{2}{*}{$\begin{array}{l}\text { Not in siege } \\
\text { (reference) }\end{array}$} & \multicolumn{2}{|c|}{ Tests for heterogeneity } \\
\hline & & $\leq 8$ & 9-15 & $16-26$ & & LR‡ P value & Wald§ $P$ value \\
\hline \multicolumn{8}{|c|}{ Ischaemic heart disease } \\
\hline Model 1 & 1.28 (1.08 to 1.51$)$ & 1.35 (0.76 to 2.38$)$ & 1.39 (1.07 to 1.79$)$ & 1.19 (0.95 to 1.50$)$ & 1.00 & 0.03 & 0.43 \\
\hline Model 2 & 1.24 (1.05 to 1.47$)$ & 1.33 (0.75 to 2.35$)$ & 1.37 (1.06 to 1.77 ) & 1.14 (0.91 to 1.44$)$ & 1.00 & 0.06 & 0.35 \\
\hline Model 3 & 1.23 (1.04 to 1.46$)$ & 1.38 (0.78 to 2.44$)$ & 1.29 (1.00 to 1.68$)$ & 1.17 (0.93 to 1.47$)$ & 1.00 & 0.11 & 0.68 \\
\hline Model 4 & $1.22(1.03$ to 1.44$)$ & 1.44 (0.81 to 2.55$)$ & 1.25 (0.97 to 1.61$)$ & 1.17 (0.93 to 1.47$)$ & 1.00 & 0.14 & 0.87 \\
\hline Model 5 & 1.19 (1.00 to 1.41$)$ & 1.38 (0.78 to 2.44$)$ & 1.25 (0.97 to 1.62$)$ & 1.13 (0.89 to 1.42$)$ & 1.00 & 0.21 & 0.69 \\
\hline \multicolumn{8}{|l|}{ Stroke } \\
\hline Model 1 & $1.19(0.93$ to 1.51$)$ & 0.55 (0.13 to 2.31$)$ & 1.67 (1.15 to 2.43$)$ & 0.99 (0.72 to 1.35$)$ & 1.00 & 0.03 & 0.02 \\
\hline Model 2 & 1.15 (0.90 to 1.46$)$ & 0.54 (0.13 to 2.27$)$ & 1.65 (1.13 to 2.40$)$ & 0.94 (0.69 to 1.30$)$ & 1.00 & 0.04 & 0.01 \\
\hline Model 3 & 1.13 (0.88 to 1.43$)$ & 0.58 (0.14 to 2.43$)$ & 1.49 (1.02 to 2.17$)$ & 0.96 (0.70 to 1.33$)$ & 1.00 & 0.15 & 0.05 \\
\hline Model 4 & 1.11 (0.87 to 1.81$)$ & $0.57(0.14$ to 2.40$)$ & 1.44 (0.99 to 2.10$)$ & 0.96 (0.70 to 1.32$)$ & 1.00 & 0.20 & 0.06 \\
\hline Model 5 & 1.09 (0.85 to 1.39$)$ & 0.55 (0.13 to 2.30$)$ & 1.48 (1.02 to 2.16$)$ & 0.92 (0.67 to 1.27$)$ & 1.00 & 0.13 & 0.03 \\
\hline \multicolumn{8}{|c|}{ Haemorrhagic stroke } \\
\hline Model 1 & 1.28 (0.82 to 1.98$)$ & 0.94 (0.12 to 7.48$)$ & 1.71 (0.90 to 3.22$)$ & 1.01 (0.55 to 1.87$)$ & 1.00 & 0.44 & 0.22 \\
\hline Model 2 & 1.27 (0.82 to 1.97$)$ & 0.99 (0.12 to 7.94$)$ & 1.69 (0.90 to 3.20$)$ & 1.01 (0.55 to 1.87$)$ & 1.00 & 0.46 & 0.23 \\
\hline Model 3 & 1.18 (0.75 to 1.82$)$ & 0.99 (0.12 to 7.83$)$ & 1.51 (0.80 to 2.86 ) & 0.96 (0.52 to 1.77$)$ & 1.00 & 0.66 & 0.30 \\
\hline Model 4 & 1.14 (0.73 to 1.77$)$ & 0.94 (0.12 to 7.42$)$ & 1.43 (0.75 to 3.42$)$ & 0.94 (0.51 to 1.75$)$ & 1.00 & 0.74 & 0.34 \\
\hline Model 5 & 1.14 (0.73 to 1.79$)$ & 0.95 (0.12 to 7.56$)$ & 1.44 (0.76 to 2.76$)$ & 0.95 (0.51 to 1.76 ) & 1.00 & 0.73 & 0.33 \\
\hline
\end{tabular}

*Excludes 672 men for whom information on socioeconomic and behavioural variables was missing.

†Model 1: birth cohort and attained age; model 2: model 1 + occupation, education, marital status, smoking, and alcohol intake; model 3: model $1+$ systolic and diastolic blood pressure; model 4: model $1+$ all biological risk indicators; model 5: model $1+$ all factors from other models.

tLikelihood ratio test that outcome was equally likely in each category $\left(\leq 8,9-15,16-26\right.$, not in siege). Under the null hypothesis the test statistic has $\chi^{2}$ distribution with 3 df.

$\S$ Wald test that siege effect was same for those aged 9-15 at siege as for those aged $\leq 8$ or $16-26$. Under the null hypothesis the test statistic has $\chi^{2}$ distribution with 1 df.

reduced risk. The period specific relative risk was 1.79 , based on the main effect and a highly significant interaction $(\mathrm{P}=0.004)$ effect $(1.55,1.16$ to 2.08$)$ (data not shown).

\section{Discussion}

Men who experienced the Leningrad siege have higher systolic and diastolic blood pressure and excess mortality from ischaemic heart disease and stroke. Blood pressure mediated part of the siege effect on mortality, while other biological risk markers (such as body mass index and cholesterol concentrations) did so to lesser extent. Lifestyle and socioeconomic circumstances did not confound the association between cardiovascular mortality and siege exposure.

Starvation around puberty (ages 9-15) was more strongly associated with high systolic blood pressure and stroke in adult life than was starvation at other ages. This casts new light on the effect of severe malnutrition in early life. We used the age limit of 9 years on the basis of work by Marshall and Tanner, who 


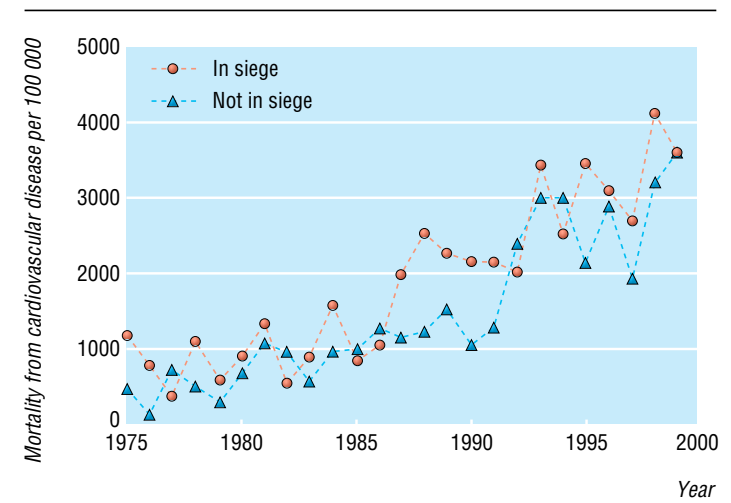

Cardiovascular mortality over time by exposure to Leningrad siege (mortality estimated from Poisson regression model)

considered "the fat spurt" to be the earliest manifestation, or trigger, of puberty that is visible before age $10 .^{19}$

Literature on anorexia nervosa details several cardiovascular abnormalities in patients, including reduction of ventricular mass, valvular dysfunctions, ${ }^{20}$ and electrocardiographic abnormalities. ${ }^{21}$ Damage of the myocardial fibres has been documented in obese patients on very low calorie diets. ${ }^{22}$ Furthermore, endocrine changes accompany self starvation around puberty. ${ }^{23}$ At least two of these changes-increased circulating concentrations of growth hormone and cortisolprofoundly influence regulation of blood pressure. Increased secretion of growth hormone is linked with hypertension. ${ }^{24} 25$ Critical stages in the process of regulating blood pressure may therefore occur during puberty, ${ }^{26}{ }^{27}$ and starvation may cause a permanent disruption of blood pressure regulation.

An early study of the siege concluded that the immediate effect of starvation was a lowering of blood pressure. However, overcompensation occurred on refeeding. In people who have to do hard physical work blood pressure may rise as a consequence of refeeding after starvation. ${ }^{28}{ }^{29}$ Limited food supplies reached Leningrad from the spring of 1942 across Lake Ladoga. Keys et al refers to the subsequent "refeeding after starvation" in $1943 .{ }^{30}$ A sample of 10000 healthy people in Leningrad examined in April 1943 showed that the distribution of blood pressure had shifted radically upwards compared with that in 1940. The prevalence of hypertension had increased fourfold among those under age 39 and twofold among those aged $\geq 40$ years. This "Leningrad blockade hypertension epidemic" remains visible in our data over three decades after the blockade.

\section{Possible biases}

We considered several methodological problems to rule out any potential bias.

Selection-The death toll during the 1941-4 siege was extreme. Death rates of survivors in 1944-75 may also have been increased. Siege survivors examined in 1975-7 constituted a group of individuals selected for better genetic, constitutional, and social resources for health than other study participants. This selection should bias our estimates of the mortality effects of starvation downwards.

Narrow exposure contrast-Food shortage was common all over Russia during the war, especially in areas occupied by the Germans. Livestock and harvests were appropriated for German needs, and not distributing food to the Russian population was part of the German war strategy. ${ }^{31}$ Therefore we are comparing boys and men exposed to protracted starvation with those who experienced less severe food shortage, including episodes of starvation, which results in conservative risk estimates.

\section{What is already known on this topic}

Impaired growth in utero is linked to raised blood pressure and increased risk of ischaemic heart disease and stroke

Results of previous studies on the effect of severe starvation in utero, infancy, or childhood on cardiovascular outcomes are inconsistent, and few studies have assessed the long term effects of starvation at later ages

Anorexia in young people is thought to affect cardiovascular health

\section{What this study adds}

Starvation during the Leningrad siege, with its accompanying stress and trauma, resulted in raised systolic and diastolic blood pressure, which was evident even three decades after the event

In a further follow up to 25 years, men who had experienced the siege had increased mortality from ischaemic heart disease and stroke

Puberty may be a highly vulnerable period for the development of later cardiovascular disease

Residual confounding-We assessed potential confounding factors at only one point in time (1975-7). Although all of them were strongly associated with mortality, they had little confounding effect. Residual confounding is therefore likely to be small.

Differential ascertainment of death - The researchers who traced the movements of cohort members and collected death certificates did not know the siege status of participants. After the last date of contact we excluded from the study individuals who moved from Leningrad. A bias could occur if this follow up was imperfect and if men who had not experienced the siege were more likely to leave Leningrad for some reason. We found no such evidence.

\section{Conclusions}

On balance, our estimates of risks caused by siege exposure are probably conservative, perhaps very much so. It is difficult to suggest pathways, other than raised blood pressure, by which starvation causes cardiovascular mortality. Other potential mediating factors (for example, endocrine changes ${ }^{32}{ }^{33}$ ) were not measured at all, and thus remain hypothetical. The nutritional component of starvation is also entangled with the trauma of the siege.

Work predating the fetal origins hypothesis had a broader focus, which included childhood exposures. Our study indicates that puberty may also be a highly vulnerable period. Our risk estimates for the period around puberty are at least as high as those calculated for fetal starvation, corresponding to reduced birth weights of 500-600 g. Starvation in puberty today may have implications for future cardiovascular disease in many developing countries. War is still a leading cause of starvation and this may have consequences for circulatory disease decades later.

We are grateful to Ilona Koupil for comments on an early draft. We benefited greatly from discussion with participants at three seminars at the Monica-Centre in Novosibirsk, the London School of Hygiene and Tropical Medicine, and the Institute for Contemporary History at Södertörns högskola, University College, Huddinge.

Contributors: DV had the original idea for the paper. PS did the data analyses, assisted by DP. PS and DV wrote the first versions of the paper together 
and discussed all the details with DS. DS was responsible for the follow up and tracing of cohort members, in which SP, NP, and VH took part. MRG contributed with her expertise in child health and development. All authors commented on the final version of the paper. PS and DV are the guarantors of the paper.

Funding: Swedish Baltic Sea Foundation; Swedish Council for Social Research.

Competing interests: None declared.

Ethical approval: Not required.

1 Stein Z, Susser M, Saengler G, Marolla F. Famine and human development. The Dutch hun ger winter of 1944-1945. London: Oxford University Press, 1975.

2 Antonov AN. Children born during the siege of Leningrad in 1942. J Pediat 1947:250-9.

3 Leon D, Koupilová I. Birth weight, blood pressure and hypertension. Epidemiological studies. In: Barker DJ, editor. Fetal origins of cardiovascular and lung disease. New York and Basel: Marcel Dekker, 2001

4 Leon DA, Lithell HO, Vagero D, Koupilova I, Mohsen R, Berglund L, et al. Reduced fetal growth rate and increased risk of death from ischaemic heart disease: cohort study of 15000 Swedish men and women born 1915- 29. BMJ 1998;317:241-5.

5 Hyppönen E, Leon DA, Kenward MG, Lithell H. Prenatal growth and risk of occlusive and haemorrhagic stroke in Swedish men and women born 1915-29: historical cohort study. BMJ 2001;323:1033-4

6 Stanner SA, Bulmer K, Andres C, Lantseva OE, Borodina V, Poteen VV, et al. Does malnutrition in utero determine diabetes and coronary heart disease in adulthood? Results from the Leningrad iege study, a cross section sudy. $B M J 1997 ; 315: 1342-8$.

Roseboom TJ, van der Meulen JH, Osmond C, Barker DJ, Ravelli AC, Bleker OP. Plasma lipid profiles in adults after prenatal exposure to the Dutch famine. Am J Clin Nutr 2000;72:1101-6

8 Roseboom TJ, van der Meulen JH, Osmond C, Barker DJ, Ravelli AC, Schroeder-Tanka JM, et al. Coronary heart disease after prenatal exposure to the Dutch famine, 1944-45. Heart 2000;84:595-8.

9 Bygren LO, Edvinsson S, Brostrom G. Change in food availability during pregnancy: Is it related to adult sudden death from cerebro- and cardiovascular disease in offspring? Am J Human Biol 2000; 12:447-53.

10 Kannisto V, Christensen K, Vaupel JW. No increased mortality in later life for cohorts born during famine. Am J Epidemiol 1997;145:987-94.

11 Cooke RA, Chambers JB. Anorexia nervosa and the heart. Br J Hosp Med 1995;54:313-7.

12 Kermack W, McKendrick A, McKinley P. Death rates in Great Britain and Sweden. Some general regularities and their significance. Lancet 1934;i:698-703.

13 Forsdahl A. Are poor living conditions in childhood and adolescence an important risk factor for arteriosclerotic heart disease? Br J Prev Soc Med 1977;31:91-5.

14 Peck AM, Vågerö D. Adult body height, self perceived health and mortality in the Swedish population. J Epidemiol Community Health 1989;43:380-4.

15 Pavlov D. Leningrad 1941: the blockade. Chicago: University of Chicago Press, 1965.

16 Abernathy JR, Thorn MD, Ekelund LG, Holme I, Stinnett SS, Shestov DB, et al. Correlates of systolic and diastolic blood pressure in men 40 to 59 years of age sampled from United States of America and Union of Soviet Socialist Republics Lipid Research Clinics populations. Am J Cardiol 1988;61:1071-5.

17 Breslow NE, Day NE. Statistical methods in cancer research. Vol II: The design and analysis of cohort studies. Lyons: International Agency for Research on Cancer, 1987.

18 Agresti A. Categorical data analysis. New York: John Wiley, 1990.
19 Marshall W, Tanner J. Puberty. In: Falkner F, Tanner JM, editors. Human Growth. A comprehensive treatise. Part 2. Postnatal growth neurobiology. New York: Plenum Press, 1986:171-209.

20 de Simone G, Scalfi L, Galderisi M, Celentano A, Di Biase G, Tammaro P, et al. Cardiac abnormalities in young women with anorexia nervosa. Br Heart J 1994;71:287-92.

21 Swenne I. Heart risk associated with weight loss in anorexia nervosa and eating disorders: electrocardiographic changes during the early phase of refeeding. Acta Paediatr 2000;89:447-52.

22 Garnett ES, Barnard DL, Ford J, Goodbody RA, Woodehouse MA. Gross fragmentation of cardiac myofibrils after therapeutic starvation for obesity. Lancet 1969;: :914-6.

23 Støving RK, Hangaard J, Hansen-Nord M, Hagen C. A review of endocrine changes in anorexia nervosa. J Psychiatr Res 1999;33:139-52.

24 Holdaway IM, Rajasoorya C. Epidemiology of acromegaly. Pituitary 1999;2:29-41.

25 Bohlooly YM, Carlson L, Olsson B, Gustafsson H, Andersson IJ, Tornell J, et al. Vascular function and blood pressure in GH transgenic mice. Endocrinology 2001;142:3317 23.

26 Nelson MJ, Ragland DR, Syme SL. Longitudinal prediction of adult blood pressure from juvenile blood pressure levels. Am J Epidemiol 1992;136:633-45.

27 Zicha J, Kunes J. Ontogenetic aspects of hypertension development: analysis in the rat Physiol Rev 1999;79:1227-82.

28 Kreipe RE, Harris JP. Myocardial impairment resulting from eating disorders. Pediatr Ann 1992;21:760-8.

29 Brozek J, Chapman C, Keys A. Drastic food restriction: effect on cardiovascular dynamics in normotensive and hypertensive conditions. J Am Med Assoc 1948:1569-74.

30 Keys A, Brozek J, Henschel A, Mickelsen O, Taylor HL. The biology of human starvation. Minneapolis: University of Minnesota Press, 1950

31 Beevor A. Stalingrad. London: Viking, 1998

32 Melamed S, Ugarten U, Shirom A, Kahana L, Lerman Y, Froom P. Chronic burnout, somatic arousal and elevated salivary cortisol levels.J Psychosom Res 1999;46:591-8.

33 Rosmond R, Bjorntorp P. The hypothalamic-pituitary-adrenal axis activity as a predictor of cardiovascular disease, type 2 diabetes and stroke. J Intern Med 2000;247:188-97. (Accepted 14 October 2003)

doi 10.1136/bmj.37942.603970.9A

Department of Medical Epidemiology and Biostatistics, Karolinska Institute, Stockholm, Sweden

Pär Sparén senior researcher

Centre for Health Equity Studies, CHESS, Stockholm University/Karolinska Institute, Stockholm, Sweden

Denny Vågerö professor

Institute of Experimental Medicine, Russian Academy of Medical Sciences, St Petersburg, Russia

Dmitri B Shestov professor

Svetlana Plavinskaja senior researche

Nina Parfenova researcher

Valeri Hoptiar programmer

Södertörns högskola, University College, Huddinge, Sweden

Dominique Paturot research assistant

Unit of Clinical Epidemiology, Department of Medicine, Karolinska Hospital,

Stockholm, Sweden

Maria Rosaria Galanti senior researcher

Correspondence to: P Sparén Par.Sparen@meb.ki.se 